\title{
Fístula infra-orbitária em cadela: Relato de caso
}

\author{
Iuliana Marjory Martins Ribeiro ${ }^{1}$, Ciro José Sousa de Carvalho ${ }^{2 *}$, Jacqueline Canuto ${ }^{1}$ \\ ${ }^{1}$ Médica Veterinária- (Autônoma) \\ ${ }^{2}$ Médico Veterinário- Doutorando em Ciência Animal- Universidade Federal do Piauí \\ *Autor para correspondência, E-mail: cirocjsc@yahoo.com.br
}

\begin{abstract}
RESUMO. Dentre as afecções orais que podem acometer os cães, pode-se destacar a fístula infraorbitária, também chamada de "fístula do carniceiro", que consiste em uma lesão osteolítica periapical (osteólise causada por inflamação decorrente da necrose pulpar e contaminação bacteriana do canal radicular) geralmente no dente. No exame clínico do animal constatou-se a presença de fístula infraorbitária. Como tratamento foi realizada a técnica de exodontia associada à administração de antimicrobianos e antinflamatórios no pré e pós-operatório.
\end{abstract}

Palavras chave: Exodontia, Doença periodontal, Canina.

\section{Fistula infra-orbital bitch in: Case report}

\begin{abstract}
Among oral diseases that can affect dogs, can highlight the infraorbital fistula, also called "fistula Butcher", consisting of a periapical osteolytic lesions (osteolysis caused by inflammation resulting from pulp necrosis and bacterial contamination of the root canal) generally the tooth. On examination of the animal found the presence of infraorbital fistula. As a treatment technique for extraction associated with the administration of antimicrobial and anti-inflammatory drugs in pre-and postoperatively was performed.
\end{abstract}

Keywords: Tooth extraction, periodontal disease, canine.

\section{Introdução}

A saúde oral dos animais está relacionada ao aumento da expectativa de vida, uma vez que as patologias orais podem interferir na saúde geral do paciente (Dias et al., 2011).

Dentre as afecções orais que podem acometer os cães, pode-se destacar a fístula infraorbitária, também chamada de "fístula do carniceiro", que consiste em uma lesão osteolítica periapical (osteólise causada por inflamação decorrente da necrose pulpar e contaminação bacteriana do canal radicular) geralmente no dente quarto prémolar superior (4 $4^{\circ} \mathrm{PMS}$ ) (Gioso, 2007).

As causas mais conhecidas de fístula infraorbitária em cães são doença periodontal grave, fraturas de coroa e traumas dentários, neoplasias maxilares, lesões periapicais e iatrogênicas (Birchard \& Sherding, 2003; Gioso, 2007). O diagnóstico diferencial da fístula infraorbitária deve ser realizado para traumatismos, lesões cutâneas e recidiva de dermatopatias após a administração prolongada de antimicrobianos (Gonzaga, 2006; Aylon, 2008).

Para o diagnóstico de fístula infraorbitária em cães, primeiramente é necessário que se realize uma anamnese bem feita, obtendo-se o maior número de informações possíveis sobre o paciente. Somado a isso, deve-se fazer a inspeção oral minuciosa com o paciente sob sedação ou anestesia geral, caso necessário (Leon-Roman \& Gioso, 2004; Pachaly, 2006). Além disso, é necessária a realização de um exame radiográfico intraoral para confirmar o envolvimento apical de uma das raízes do dente carniceiro antes que este seja extraído (Gioso, 2007).

Segundo Aylon (2008), os tratamentos para animais com fístula infraorbitária incluem a exodontia (extração dentária) ou a endodontia (tratamento de canal), associadas à administração de antimicrobianos e antinflamatórios no pré e pós-operatório. Para o tratamento de cães e gatos com periodontite, são indicados os antimicrobianos sistêmicos. Recomenda-se incluir fármacos à base de amoxicilina com 
clavulanato, clindamicina ou metronidazol (Ettinger, 2004). Na indução anestésica indica-se administrar uma dose profilática de antimicrobianos contra micro-organismos aeróbios e anaeróbios Gram-positivos, como a amoxicilina (Fssum, 2001).

A exodontia deve ser realizada sob anestesia geral, com ou sem bloqueio regional ou anestesia local (Gioso, 2007). A anestesia local é indicada para diminuir a quantidade de medicação anestésica, visando à manutenção do plano cirúrgico e o alívio da dor pós-operatória. Como o paciente será submetido à anestesia geral, devem-se realizar exames pré-operatórios como avaliação hematológica, ou outros exames subsidiários à história clínica (Holmstrom et al., 1998).

O procedimento cirúrgico consiste, basicamente, na sindesmotomia, luxação e posterior remoção do dente. Como o $4^{\circ}$ PMS superior é um dente trirradicular, pode-se luxar todas as raízes com o elevador de raiz e, alternativamente, indica-se a odontossecção, que é essencial na maior parte dos casos. Se houver dificuldade de remoção, a terceira raiz também pode ser seccionada. Após luxar as raízes já seccionadas, pode ser utilizado o fórceps para retirá-las. No entanto, muitos dentes são removidos sem uso deste instrumento. Quando não há comprometimento periodontal, este procedimento leva bastante tempo (Gioso, 2007).

\section{Relato de caso}

Foi realizado o atendimento em uma clínica particular na cidade de Teresina-PI de uma cadela, sem raça definida, com 12 anos de idade, pesando $2 \mathrm{Kg}$ e não castrada.A queixa principal relatada pela proprietária foi que seu animal apresentava uma lesão cutânea na região infraorbitária esquerda, que numa primeira fase foi observada como uma bolsa com líquido. Ela relatou que a lesão sumiu, reaparecendo após 2 meses. Novamente a bolsa regrediu, mas voltou a aumentar, desta vez apresentando inchaço ao redor do olho esquerdo, vindo a fistular (figura 1).

Ao exame físico específico observou-se uma lesão cutânea crônica na região infra-orbitária esquerda com drenagem de secreção serosanguinolenta externa, sensibilidade à palpação e grande quantidade de cálculos dentários recobrindo as estruturas dentárias, inclusive $0 \quad 4^{\circ}$ PMS esquerdo. $\mathrm{O}$ animal encontrava-se apático, porém com um bom estado nutricional, temperatura retal $38,4{ }^{\circ} \mathrm{C}$, mucosas normocoradas e ausência de outras lesões na pele. Os demais sistemas avaliados estavam dentro da normalidade. Foram realizados exames pré-operatórios: no hemograma apresentou trombocitose; no exame bioquímico, a T.G.O/AST, T.G.P/ALT e a uréia se apresentaram bastante aumentadas, com valores $68,0 \quad \mathrm{U} / \mathrm{L}, \quad 70,0 \quad \mathrm{U} / \mathrm{L} \quad$ e $\quad 134,0 \quad \mathrm{mg} / \mathrm{dL}$, respectivamente.

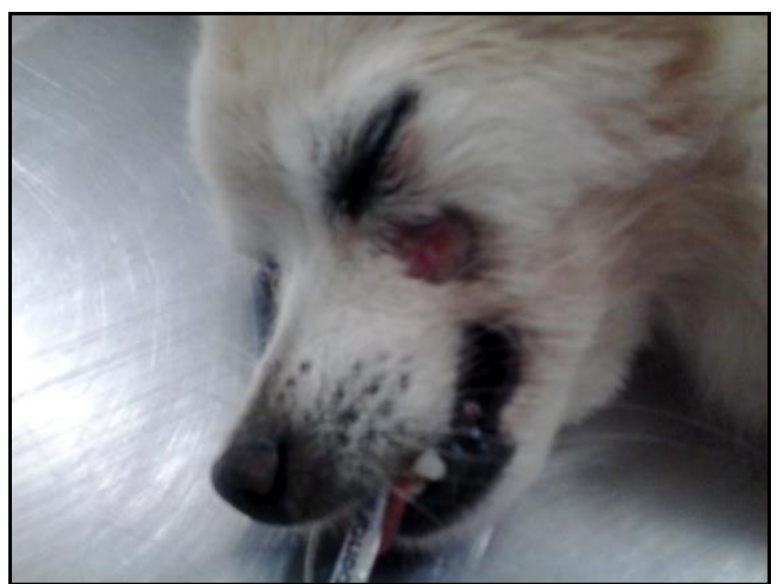

Figura 1. Lesão cutânea na região infraorbitária esquerda.

A partir da anamnese e dos exames realizados inicialmente, chegou-se a conclusão de que o animal possuía doença periodontal severa, com fístula infraorbitária. $\mathrm{O}$ tratamento realizado no consultório foi antibiótico para afecções bucodentárias (1 drágea/2 Kg, via oral, SID), e o tratamento continuou até completar os 10 dias. No pré-operatório administrou-se antibiótico à base de penicilina $(0,1 \mathrm{~mL} / \mathrm{Kg}, \mathrm{IM})$, meloxicam $(0,05 \mathrm{ml} / \mathrm{Kg}, \mathrm{SC})$ e cloridrato de tramadol $(0,1$ $\mathrm{mL} / \mathrm{Kg}$, IM).Utilizou-secloridrato de cetamina $(0,15 \mathrm{~mL} / \mathrm{Kg}, \mathrm{IV})$, acepromazina $(0,1 \mathrm{~mL} / \mathrm{Kg}$, IV) e diazepan $(0,5 \mathrm{mg} / \mathrm{Kg}$, IV) e Anestesia inalatória com isoflurano.

Durante todo o procedimento cirúrgico o animal recebeu fluido intravenoso de soro fisiológico $0,9 \% \mathrm{NaCl}$. O Animal foi colocado em decúbito dorsal e com o auxílio de um abridor bucal, fez-se a antissepsia da cavidade oral, e realizou-se a sindesmotomia, luxando-se todas as raízes do $4^{\circ} \mathrm{PMS}$ com o elevador de raiz e após sua secção, utilizou-se o fórceps, removendo-se do dente. Como havia doença periodontal, não houve tanta dificuldade em se retirar o $4^{\circ}$ PMS. Foi necessária também a retirada de mais 2 dentes, o $3^{\circ} \mathrm{PMS}$ e o $3^{\circ} \mathrm{PMI}$ direitos, devido o comprometimento dos mesmos. Na sutura 
utilizou-se fio absorvível com pontos simples separados. Após a exodontia, realizou-se a tartarectomia (figura 2).

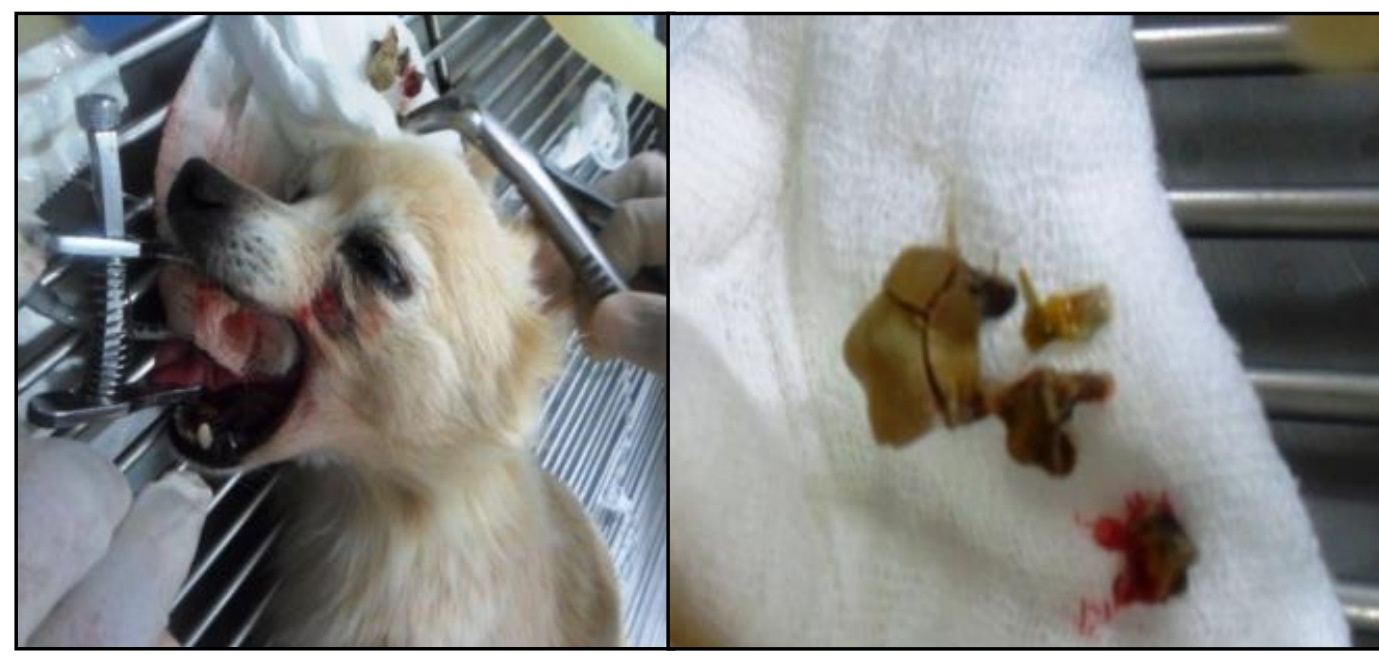

Figura 2. Realização da exodontia

Após a realização da exodontia e tartarectomia, foi feita a escovação com pasta profilática e a higienização de toda a cavidade oral com solução a base de digluconato de clorexidina. A ferida cutânea foi debridada e higienizada com solução fisiológica.Foi prescrito continuar o tratamento com o antibiótico (1 drágea/2 Kg, via oral, SID, até completar os 10 dias);foi prescrito também uma solução para higiene oral composto por xilitol $(5 \mathrm{ml} / 500 \mathrm{ml}$ de água, SID) e utilização de colar protetor e dieta líquida por 3 dias.

\section{Discussão}

O diagnóstico de fístula infraorbitária foi feito baseado nos achados clínicos, pois de acordo com os relatos de Gioso (2007), a progressão da fístula infraorbitária é lenta, podendo se estender de meses a anos (Birchard \& Sherding, 2003). Além disso, a manifestação clínica do animal em estudo comprova que sinal clínico mais evidente dessa afecção oral é o aumento de volume e fistulação cutânea na região infra-orbitária, drenando quantidades variáveis de sangue e pus (Schumacher \& Honnas, 1993; Santos, 2007).

No paciente citado foram realizados os exames laboratoriais, apresentando trombocitose, sugestivo de doença crônica. Não foi possível a realização do exame radiográfico intraoral, fundamental para confirmar se há comprometimento apical de uma ou mais raízes do dente $4^{\circ} \mathrm{PMS}$ (GIOSO, 2007). Porém, não houve duvidas quanto ao diagnóstico da fístula infraorbitária.

$\mathrm{O}$ tratamento que foi utilizado para o caso em questão foi a exodontia associada ao antimicrobiano sistêmico à base de estreptomicina e metronidazol, indicado para afecções bucodentárias de cães e gatos. De acordo com Aylon (2008), os tratamentos para animais com fístula infraorbitária incluem a exodontia (extração dentária) ou a endodontia (tratamento de canal), associadas à administração de antimicrobianos e antinflamatórios no pré e pós-operatório. Recomenda-se incluir fármacos à base de amoxicilina com clavulanato, clindamicina ou metronidazol (Ettinger, 2004). Foi associado também ao tratamento uma água de bebida adjuvante no controle de placa bacteriana e mau hálito em cães e gatos, e o colar protetor, restringindo seus movimentos, facilitando $\mathrm{o}$ processo de recuperação. A dieta líquida é recomendada após o procedimento por três a dez dias, dependendo do número de dentes extraídos e complexidade destas extrações dentárias (Birchard \& Sherding, 2003).

A tartarectomia também foi realizada devido o grande acúmulo de cálculos nos dentes do animal. Após este procedimento realizou-se a higiene oral com uma solução a base de digluconato de clorexidina a $0,12 \%$ para higienização oral de cães e gatos, auxiliando na manutenção da saúde bucal e no controle do mau hálito (figura 3). 


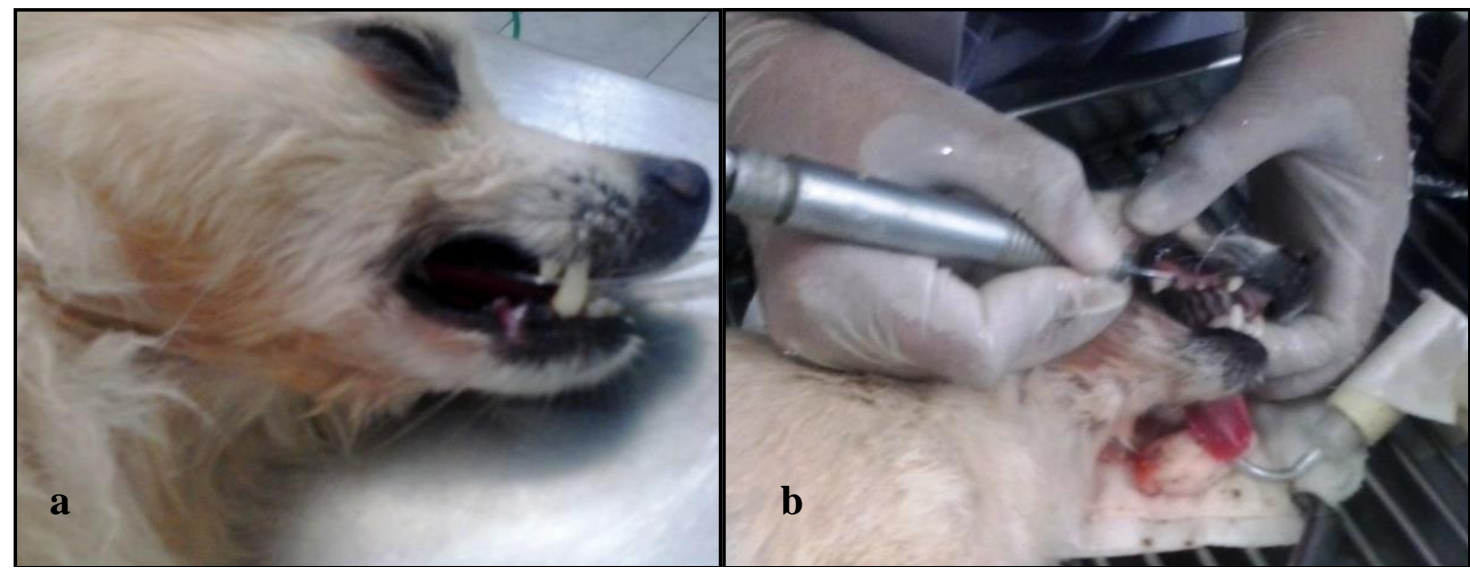

Figura 3. (a) Realização da tartarectomia. (b) Pós tartarectomia

Após 30 dias o animal retornou à clínica para reavaliação odontológica e a proprietária relatou que uma semana após o procedimento cirúrgico a fístula já tinha desparecido. A ferida cutânea estava aparentemente cicatrizada e sem sinais de drenagem de secreção externa, demonstrando assim o sucesso no tratamento (figura 4).

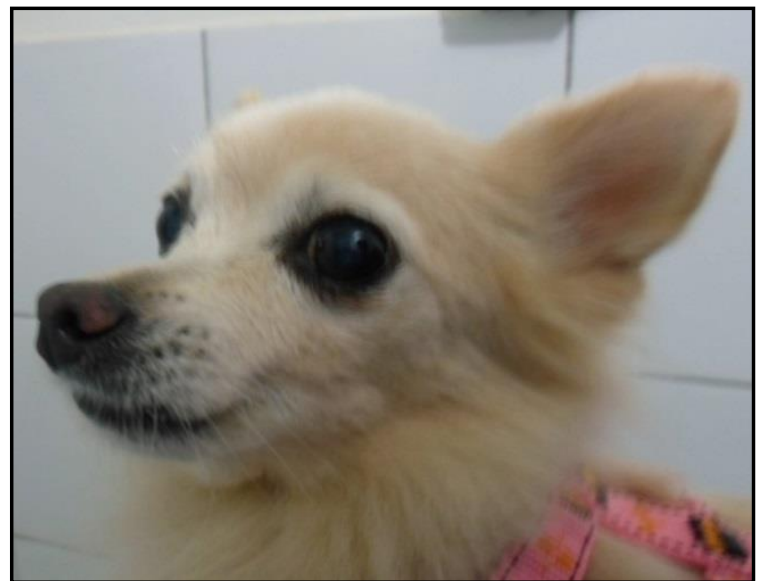

Figura 4. Paciente após tratamento, demonstrando melhora clínica.

\section{Conclusão}

É possível concluir no caso relatado, a importância do diagnóstico clínico de fístula infra-orbitária decorrente de cálculos dentários recobrindo as estruturas dentárias, inclusive o $4^{\circ}$ PMS esquerdo, bem como a eficácia do tratamentorealizado(exodontia), resultando na melhora clínica em uma cadela de idade avançada.

\section{Referências Bibliográficas}

Aylon, E. G. Lesão periapical do quarto prémolar superior esquerdo com formação de fístula: relato de caso. 2008. 42f. Monografia (Especialização em Odontologia Veterinária) Associação Nacional de Clínicos Veterinários de Pequenos Animais de São Paulo ANCLIVEPA - SP, São Paulo, 2008.

Birchard, S. J. \& Sherding, R. G. Manual Saunders: Clínica de Pequenos Animais. 2. ed. São Paulo: Roca, 2003.

Dias, F. G.; Vianna, G.D.; Paula, T. M.; Dias, L. G. G. G. \& Pereira, L. F. Fístula infraorbitária em cão - Relato de caso. Revista Científica Eletrônica de Medicina Veterinária, Ano IX, n.16, p.1-13, 2011.

Ettinger, S. J. \& Feldman, E. C. Tratado de Medicina Interna Veterinária: Doenças do Cão e do Gato. 5. ed. v.2. São Paulo: Manole, 2004.

Fossum, T. W. Cirurgia de Pequenos Animais. 1 ed. São Paulo: Roca, 2002. 1335 p.

Gioso, M. A. Odontologia Veterinária para o Clínico de Pequenos Animais. $2^{\mathrm{a}}$ ed. São Paulo: Manole, 2007. 145 p.

Gonzaga, P. O. Tratamento endodôntico em pequenos animais. 2006. 57f. Monografia (Especialização em clínica e cirurgia de Pequenos animais) - Universidade Castelo Branco, São Paulo, 2006.

Holmstrom, S. E; Frost, P, \& Eisner, E. R. Veterinary dental techniques for the small animal practitioner. 2 ed. Philadelphia: Saunders, 1998.

Leon-Roman, M. A. \& Gioso, M. A. Endodontia - anatomia, fisiopatologia e terapia para afecções dos tecidos internos do dente. Medvep - Revista Científica de Medicina Veterinária - Pequenos Animais e Animais de Estimação, p.195-203, 2004.

Lyon, K. F. Dental home care. Journal of Veterinary Dentistry, v.8, n. 2, p.26-30, 1991. 
Pachaly, J. R. Odontoestomatologia em animais selvagens. In: Cubas, Z. S.; Silva, J. C. R. \& Catâodias, Z. S. Tratado de animais selvagens. São Paulo: Roca, cap.64, 2006.

Santos, I. C. Doença periodontal em cães. 2007. 50f. Monografia (Especialização em Clínica Médica de Pequenos Animais) - Universidade Castelo Branco, São Paulo, 2007.

Schumacher, J.; HONNAS, C.M. Veterinary Clinics of North America: Equine Practice. v. 9, n. 1, p.133-152, 1993.
Recebido em Maio 27, 2014.

Aceito em Julho 22, 2014.

License information: This is an open-access article distributed under the terms of the Creative Commons Attribution License, which permits unrestricted use, distribution, and reproduction in any medium, provided the original work is properly cited. 